\title{
Integrating a Co-occurring Disorders Intervention in Drug Courts: An Open Pilot Trial
}

\author{
David Smelson $^{1} \cdot$ Ian Farquhar ${ }^{1} \cdot$ William Fisher $^{1} \cdot$ Karen Pressman $^{2} \cdot$ Debra A. Pinals $^{1,3} \cdot$ Barbara Samek $^{4} \cdot$ \\ Mary-Kate Duffy ${ }^{1}$ Leon Sawh ${ }^{5}$
}

Received: 27 September 2017 / Accepted: 27 February 2018 / Published online: 7 March 2018

(c) This is a U.S. Government work and not under copyright protection in the US; foreign copyright protection may apply 2018

\begin{abstract}
Little research has focused on systematically integrating clinical treatment within existing drug court procedures. This could be particularly useful for clients with substance use disorders, who comprise those on court dockets and often have co-existing mental health issues. This article reports on the preliminary outcomes of integrating MISSION-Criminal Justice (MISSION-CJ), a co-occurring mental health and substance use wraparound intervention, within two Massachusetts drug courts. In this open pilot, clients completed intake and 6-month follow-up assessments. The participants were primarily Caucasian (86\%), male (82\%), had at least 2 prior arrests, and received outpatient treatment for mental health (54\%), alcohol use (51\%), or drug use (88\%) prior to enrolling in MISSION-CJ. Six-month follow-up data suggested that participants showed statistically significant reductions in average number of nights spent in jail, alcohol use, and drug use, as well as an increase in full time employment.
\end{abstract}

Keywords Alternatives to incarceration $\cdot$ Drug courts $\cdot$ Co-occurring disorders treatment

\section{Introduction}

Various alternative to incarceration programs have gained popularity in the United States over the past several years, offering offenders with specific backgrounds (e.g., veterans) and problem areas (e.g., substance use, mental health, or a co-occurring disorder) a chance to address these issues in lieu of incarceration, while also providing society an opportunity to reduce prison overcrowding and spending (Piquero 2010). Drug courts are a particular type of alternative to incarceration program that have grown dramatically over

David Smelson

david.smelson@umassmed.edu

1 Department of Psychiatry, University of Massachusetts Medical School, 55 N Lake Avenue, Worcester, MA 01605, USA

2 Bureau of Substance Abuse Services, Massachusetts Department of Public Health, Boston, MA, USA

3 Massachusetts Department of Mental Health, Boston, MA, USA

4 Gavin Foundation, Inc., Boston, MA, USA

5 School of Criminology and Justice Studies, University of Massachusetts Lowell, Lowell, MA, USA the past 25 years in response to the high rates of substance use among criminal justice involved individuals (Fox et al. 2015). Clients enrolled in drug courts often have comorbid mental health problems, with reported rates of $30-40 \%$ of the docket (Belenko 2001). While specialized court dockets for individuals with co-occurring disorders courts have been developed to address the multifaceted needs of the clients, it remains more common for drug courts and mental health courts to be run separately, while still enrolling clients with a co-occurring disorder (COD) (Steadman et al. 2013).

Both drug courts and mental health courts are designed to link offenders to community-based mental health or substance use treatment services (Steadman et al. 2001) and have yielded a number of positive outcomes, including reductions in recidivism and substance use, and improved psychological functioning (Case et al. 2009; Knudsen and Wingenfeld 2016). Furthermore, a recent econometric simulation study estimating the potential cost savings suggested that diverting offenders from prison to drug treatment resulted in a $\$ 22.5$ billion benefit to society in general and $\$ 12.9$ billion in savings to the criminal justice system (Zarkin et al. 2015).

Drug courts, like all specialty courts, share a number of common practices, including a specialized court docket with 
regular appearances in front of a specific judge who oversees the drug court session, monitors participant adherence, receives input from probation officers, and conducts ongoing monitoring of client participation in drug treatment, with sanctions and rewards to help move the participant toward recovery (Brown 2010). However, to date, limited research has focused specifically on clinical treatment programs that are uniquely designed and oriented to serve drug court participants alongside the court personnel such as probation, as opposed to focusing on the drug court outcomes when treatment as usual is provided in the community by a provider who takes drug court referrals just like any other referral source. Of note, while not reported in the literature, anecdotal observations suggest that integrating treatment providers within drug courts could improve outcomes by increasing the alignment between the treatment community and court case processing. This is particularly relevant for clients in drug courts who have co-occurring mental health problems; they are often more difficult to engage in care compared to those with only an addiction problem and require wraparound support services in order to comprehensively address all of their treatment needs (Peters et al. 2012). Clients with co-occurring disorders also often have high unemployment rates and difficulty securing and sustaining employment, which further compounds their recovery difficulties (O'Connor et al. 2012).

Researchers have recently urged the field to develop comprehensive behavioral and criminal justice interventions that meet the complex mental health, substance use, and criminal justice needs of offenders, with the ultimate goal of reducing service fragmentation (Epperson et al. 2014; Wolff et al. 2013). Maintaining Independence and Sobriety through Systems Integration, Outreach, and Networking-Criminal Justice (MISSION-CJ) is an example of such a wraparound intervention. MISSION-CJ is unique in that one of the core components is assertive community outreach along with attention to criminal justice outcomes, allowing providers to go to the drug court sessions and the community as opposed to traditional treatment often occurring in an office-based setting for individuals who are also enrolled in a drug court. This paper reports the results of a pilot study assessing the preliminary efficacy of integrating MISSION-CJ within two Massachusetts drug courts and the preliminary 6-month program outcomes.

\section{Methods}

\section{Program Description}

\section{MISSION-CJ Model Development}

MISSION-CJ was adapted from our wraparound approach called MISSION, originally developed to help clients with a co-occurring mental health and substance abuse problem engage in community supports while simultaneously addressing some of their clinical needs, and has recently been included in the Substance Use and Mental Health Services National Registry for Evidence Based Practices (Smelson et al. 2007; MISSION 2016). Our previous research has shown MISSION to improve mental health, substance use, housing, and employment outcomes for homeless clients as well as veterans (Smelson et al. 2012, 2013, 2015). MISSION was recently adapted and pilot tested with criminal-justice involved veterans who were diverted from jail, but not seen in a specialty court session (Smelson et al. 2015). The adaptations of MISSION for homeless clients, to MISSION-CJ for justice-involved clients included the integration of a criminogenic risk and need assessment, and was incorporated into a new MISSION-CJ Treatment Manual (Pinals et al. 2014) and Participant Workbook (Smelson et al. 2014).

\section{MISSION-CJ Service Delivery Structure and Treatment Components}

MISSION-CJ is delivered jointly by a case manager and peer support specialist, who carry caseloads of approximately 15 clients per case manager/peer support specialist team. This small caseload size is a deliberate program design made in an effort to offer intensive, communitybased support. The MISSION-CJ services are intended to be integrated within the specialty court docket and in parallel with probation. These services are generally offered for 12 months as part of a court-order and a term of probation. MISSION-CJ staff works closely with probation throughout the program duration to support the client's community success and adherence to terms of probation. The MISSION-CJ curriculum includes approximately $2.5 \mathrm{~h}$ of individual and group sessions per week for 10 months, reduced to twice per month during months 11 and 12. "Dosing" of MISSION-CJ programming and treatment referrals can be titrated depending on the risk level of the client with regard to recidivism. Modeled after the original MISSION intervention for homeless clients, the same core treatment components were used in the MISSION-CJ approach (Smelson et al. 2015). 
The first core component of MISSION-CJ is Critical Time Intervention (CTI) case management (Susser et al. 1997), which offers intensive community based services immediately upon re-entry into the community or after an arrest and subsequent court appearance. The goal of CTI is to work with the client to establish firm linkages with supports in the community, including service providers, given that MISSION-CJ services are time-limited. Complementary to the CTI approach is the second treatment component of MISSION-CJ; Dual Recovery Therapy (DRT) (Ziedonis and Stern 2001), with 13 sessions delivered in the first 3 months of enrollment into the MISSION-CJ program. DRT sessions seek to raise awareness of the impact of mental illness, substance use, and other harmful behaviors on clients' lives, and offer tools to aid in recovery. Moreover, the DRT sessions focus on such topics as how an individual's mental health and substance use are interrelated, how to help motivate clients to engage in recovery while addressing the possible variation across problem areas, and how to help clients develop coping skills to address their mental health and addiction issues and prevent future relapses. DRT booster sessions are conducted throughout the duration of MISSION-CJ to reinforce DRT topics covered in the first 13 sessions that the client needs to review further.

The third treatment component of MISSION-CJ is Peer Support (Chinman et al. 2010, 2014), delivered in conjunction with CTI and DRT. Peer Support Specialists deliver 11 recovery oriented sessions from a frame of reference of someone who has "been there," and can serve as a role model for others in recovery. Peer Support Specialists also offer clients assistance in adjusting to new routines, such as avoiding triggers for engaging in criminal and/or substance use behavior, and emphasizing the importance of engaging with needed treatment supports. Vocational and educational supports are the fourth component of MISSION-CJ and are offered to help clients find and maintain employment and achieve educational goals, thus contributing to daily living stability, reducing recidivism risk, and improving quality of life outcomes. In MISSION-CJ, the case manager and peer specialist teams not only link clients to existing vocational and educational services in the community, but also offer job search, placement, and coaching. All MISSION-CJ Case Managers and Peer Support Specialists are also cross-trained to deliver the fifth component of MISSION-CJ, trauma informed care. While MISSION-CJ is not a co-occurring Post Traumatic Stress Disorder and Addiction Treatment intervention, case managers and peer specialists are trained to work with clients with trauma histories in a way that is trauma-sensitive, as well as to assess and refer clients to other treatment providers who offer evidence-based treatments for the management of trauma symptoms. MISSIONCJ case managers and peer specialists also provide trauma informed support for those clients with sub-threshold symptoms or who received a previous referral. In addition to receiving CTI, DRT, peer support, vocational and education support, and trauma informed care, MISSION-CJ clients are also routinely linked to other community-based psychiatric services and psychosocial supports including medication management, PTSD treatment, assistance with benefits and entitlements, and family therapy, to name a few.

However, as noted above, the entire MISSION-CJ model operates in the context of the client's level of criminal recidivism risk and needs. Therefore, the sixth component, specific to the MISSION-CJ adaptation of the original MISSION model is the incorporation of the Risk-Need-Responsivity (RNR) framework, which posits that criminal justice agencies and treatment programs should target criminogenic needs (Andrews et al. 1990; Andrews and Bonta 2006; Bonta and Andrews 2007; Taxman and Thanner 2006). Moreover, the RNR model of assessment and treatment has three core principles: Risk: the level of service should be matched to the participant's level of risk to re-offend. Need: assess each participant's specific "criminogenic" needs such as impulsivity, antisocial cognitions, lack of prosocial peer group engagement, and disconnection from family, to name a few, and build treatment around those needs. Responsivity: maximize each participant's ability to learn from treatment by providing cognitive behavioral interventions and tailoring those interventions to the unique learning style, motivation, abilities, and strengths of the offender. The RNR framework guides MISSION-CJ staff in their initial treatment planning regarding the use of each MISSION-CJ treatment component, and ongoing monitoring on their progress in addressing those needs. MISSION-CJ staff also ran a group for program participants whenever space permitted inside the court house. As noted above, these MISSION-CJ services were offered for a maximum of 12 months as long as the client was enrolled in the drug court.

\section{MISSION-CJ's Role Within Drug Courts}

In integrating MISSION-CJ in the two Massachusetts Drug Court settings in the Boston Metro Area, it was first critical to identify the role of the providers in the courts. This was done through a series of meetings with judges, probation, other drug court personnel, and the developers of MISSIONCJ. Through these meetings and based on prior experience adapting the model for the criminal justice population, it was decided that MISSION-CJ case management and peer specialist teams would go into the courts as well as offer services outside of the court session. With regard to work within the court, MISSION-CJ staff participated in pre-court meetings between judges, attorneys, the court-appointed probation officer, and treatment providers to learn about the specific needs of each client, and attended each drug court 
session. Participation in MISSION-CJ is voluntary, as is participation in drug court. Early studies have begun to examine voluntariness and perceived coercion for participants in such programs (Trojano et al. 2017). At the same time, by agreeing to participate, information sharing releases are secured to allow case coordination across treatment and criminal justice and court personnel. This approach allows MISSION-CJ staff, the judge, and probation to discuss client disposition and to make real time changes to the treatment plan. A decision to not participate in drug court could result in having one's criminal case processed in the usual pathway, which generally entailed incarceration. Thus, participation in the specialty court as a whole was viewed as an alternative to incarceration, and MISSION-CJ was an augmentation of treatment resources for participants.

\section{Study Design}

This study employed an open pilot design to examine the preliminary efficacy of integrating MISSION-CJ in two existing Massachusetts drug court programs. Clients, represented by counsel, were initially enrolled in the two Massachusetts Drug Courts. Once enrolled in the drug court, clients who had a co-occurring mental health and substance abuse problem, and appeared to meet program eligibility criteria below, were invited by the judge to participate in MISSION-CJ services. Enrollment into the MISSION-CJ services included (1) persons of both genders who were 18 years of age or older and (2) were enrolled in one of two drug court programs; (3) met criteria for a DSM-IVTR Axis I psychiatric disorder, including depression, anxiety, and/or a trauma-related issue; and (4) exhibited current substance use or dependence. Defendants were excluded if they: (1) had an acute severe psychiatric condition in need of immediate treatment or were acutely psychotic; (2) were affected by moderate to severe intellectual disability or cognitive impairment as a result of traumatic brain injury (TBI); (3) were acutely suicidal; or (4) needed immediate medical attention related to substance use (i.e., withdrawal). These exclusion criteria were based on developing a target population that was appropriate for drug court, had a co-occurring mental health condition, and also had the capacity to consent to the treatment program. This project was built into services within the two drug courts, and all information and data collected was done as part of the treatment assessment upon intake. This information was then pulled from records as a means of examining data that was required as part of the services activity to ensure and review program quality in an ongoing manner for the program administrators and funders. As such, when reviewed by multiple state and university Institutional Review Boards the data collection was deemed to be program evaluation, as opposed to research. Participants were therefore not required to provide research informed consent prior to their participation, but did sign a clinical informed consent to participate in the services and to have their clinical information pulled for program and services evaluation. Once enrolled, all offenders with a COD completed a comprehensive baseline intake assessment prior to starting services in the MISSION-CJ program and a 6 month follow up assessment using the measures below.

\section{Criminal Justice, Behavioral Health, and Related Measures}

Baseline information regarding criminal justice involvement, alcohol and illicit drug use, and other behavioral health issues was derived from a collection of instruments required as a term of the Substance Abuse and Mental Health Services Administration (SAMHSA) grant that funded this project. This included selected items from the Addiction Severity Index (ASI; McLellan et al. 1992), the Behavior and Symptom Identification Scale, and the SAMHSA Government Performance Act Questions (GPRA; Substance Abuse \& Mental Health Services Administration 2006). Quantity, frequency, and severity of substance use were measured using the drug use section of the ASI (McLellan et al. 1992), In addition, in compliance with national requirements, mental health and substance use service, treatment, criminal justice involvement, and prevention data were collected via the GPRA data reporting system (Substance Abuse \& Mental Health Services Administration 2006). Preliminary program outcomes reported here were measured by changes in the aforementioned instruments from baseline to 6 months post-treatment.

\section{Data Analysis}

To determine the symptom patterns of participants, frequencies and descriptive analyses were computed for dichotomous and continuous variables using SPSS Statistics 23. Data were analyzed using paired sample $t$ tests for continuous measures and McNemar's tests for dichotomous variables.

\section{Results}

\section{Baseline Characteristics}

\section{Demographics}

Demographic data for 86 clients enrolled in MISSION-CJ services are presented in Table 1 . Clients $(n=86)$ were predominantly male $(82.6 \%)$ and Caucasian $(86.0 \%)$, mostly with a high school diploma/GED or higher (79.0\%). Mean 
Table 1 Baseline participant characteristics

\begin{tabular}{|c|c|c|c|}
\hline Variable & $n$ & $\%$ & $M(S D)$ \\
\hline \multicolumn{4}{|l|}{ Criminal justice } \\
\hline Arrested at least one time & 85 & 100.0 & \\
\hline Incarcerated for at least 1 month & 83 & 97.6 & \\
\hline Lifetime arrests & & & 17.79 (15.67) \\
\hline Lifetime convictions & & & $14.76(15.60)$ \\
\hline Lifetime months incarcerated & & & $31.34(49.83)$ \\
\hline Nights in jail in the last 30 days & & & $10.71(13.66)$ \\
\hline Nights in jail in the last 6 months & & & $61.92(50.60)$ \\
\hline \multicolumn{4}{|l|}{ History of arrests that led to charges } \\
\hline Shoplifting/vandalism & 40 & 47.1 & \\
\hline Parole/probation violation & 76 & 89.4 & \\
\hline Drug charges & 67 & 78.8 & \\
\hline Forgery & 21 & 24.7 & \\
\hline Weapons & 18 & 21.2 & \\
\hline Burglary/larceny/B\&E & 54 & 63.5 & \\
\hline Robbery & 18 & 21.2 & \\
\hline Assault & 36 & 42.4 & \\
\hline Arson & 0 & 0.0 & \\
\hline Rape & 0 & 0.0 & \\
\hline Homicide & 0 & 0.0 & \\
\hline Prostitution & 1 & 1.2 & \\
\hline Contempt of court & 1 & 1.2 & \\
\hline Disorderly conduct/public intoxication & 31 & 36.5 & \\
\hline Driving while intoxicated & 22 & 25.9 & \\
\hline Other driving violations & 39 & 45.9 & \\
\hline Two or more prior arrests & 85 & 100.0 & \\
\hline Ever had a restraining order & 25 & 29.4 & \\
\hline \multicolumn{4}{|l|}{ Gender } \\
\hline Male & 71 & 82.6 & \\
\hline Female & 15 & 17.4 & \\
\hline Age (years) & & & $33.64(8.51)$ \\
\hline \multicolumn{4}{|l|}{ Ethnicity } \\
\hline African American & 8 & 9.3 & \\
\hline Caucasian & 74 & 86.0 & \\
\hline Hispanic & 5 & 5.8 & \\
\hline Other & 4 & 4.7 & \\
\hline \multicolumn{4}{|l|}{ Education } \\
\hline$<12$ years & 18 & 20.9 & \\
\hline High school diploma/equivalent & 42 & 48.8 & \\
\hline Post-high school & 26 & 30.2 & \\
\hline \multicolumn{4}{|l|}{ Employment (current) } \\
\hline Employed & 25 & 29.1 & \\
\hline Unemployed & 61 & 70.9 & \\
\hline \multicolumn{4}{|l|}{ Housing } \\
\hline Shelter & 0 & 0.0 & \\
\hline On street/outside & 0 & 0.0 & \\
\hline Institution & 31 & 36.0 & \\
\hline Housed & 55 & 64.0 & \\
\hline Own/rent apartment, room, or house & 4 & 4.7 & \\
\hline Someone else's apartment, room, or house & 1 & 1.2 & \\
\hline Halfway house & 35 & 40.7 & \\
\hline
\end{tabular}


Table 1 (continued)

\begin{tabular}{|c|c|c|c|}
\hline Variable & $n$ & $\%$ & $M(S D)$ \\
\hline Residential treatment & 13 & 15.1 & \\
\hline Other/missing & 2 & 2.3 & \\
\hline \multicolumn{4}{|l|}{ Service use (past month) } \\
\hline Inpatient for physical complaint & 3 & 3.5 & \\
\hline Outpatient for physical complaint & 19 & 22.1 & \\
\hline Emergency room for physical complaint & 6 & 7.0 & \\
\hline Inpatient for psychiatric complaint & 1 & 1.2 & \\
\hline Outpatient for psychiatric complaint & 12 & 14.0 & \\
\hline Emergency room for psychiatric complaint & 0 & 0.0 & \\
\hline Inpatient for substance use & 14 & 16.3 & \\
\hline Outpatient for substance use & 6 & 7.0 & \\
\hline Emergency room for substance use & 1 & 1.2 & \\
\hline \multicolumn{4}{|l|}{ Substance use and mental health } \\
\hline Years used alcohol to intoxication & & & $11.57(9.32)$ \\
\hline Ever received outpatient treatment for mental health & 46 & 54.1 & \\
\hline Ever received inpatient treatment for mental health & 21 & 24.7 & \\
\hline Ever received ER treatment for mental health & 19 & 22.4 & \\
\hline Ever received treatment for alcohol use & 43 & 51.2 & \\
\hline Ever received treatment for drug use & 75 & 88.2 & \\
\hline \multicolumn{4}{|l|}{ Most commonly used drugs (past month) } \\
\hline Alcohol & 3 & 3.5 & \\
\hline Cannabis & 1 & 1.2 & \\
\hline Heroin & 1 & 1.2 & \\
\hline Cocaine/crack & 3 & 3.6 & \\
\hline Benzodiazepines & 2 & 2.4 & \\
\hline Hallucinogens & 1 & 1.2 & \\
\hline Other drugs & 2 & 2.4 & \\
\hline Any illicit drug & 6 & 7.0 & \\
\hline \multicolumn{4}{|l|}{ Trauma } \\
\hline At least one traumatic event in lifetime & 43 & 50.0 & \\
\hline Experienced physical abuse & 27 & 31.8 & \\
\hline Experienced sexual abuse & 14 & 16.5 & \\
\hline
\end{tabular}

age was 33.64 years $(S D=8.51), 64.0 \%$ reported being housed and $70.9 \%$ were unemployed.

\section{Criminal Justice Involvement}

Clients typically had relatively lengthy histories of criminal justice involvement that included a broad range of severity of criminal charges in their histories. All had been arrested at least twice prior to being enrolled in drug courts, and had an average of 17.79 lifetime arrests $(S D=15.67)$. The average age at first arrest among the sample was 17.88 years $(S D=5.16)$. On average, clients had spent a total of 31.34 months $(S D=49.83)$ incarcerated during their lifetime. Given the average age of the clients, this suggests that many had begun their criminal justice involvement as juveniles (Table 2).

\section{Preliminary MISSION-CJ Program Outcomes}

As this was an open pilot to evaluate the preliminary efficacy of integrating MISSION-CJ in a drug court setting, no comparison group was included. Therefore, pre-test/post-test outcome data were computed for 67 of the 86 clients originally enrolled, who completed MISSION-CJ services and the 6-month follow-up assessment. The $22 \%$ attrition rate at 6 months was due to participants being lost to follow-up. While we were unable to contact clients whom were lost to follow-up, and thus cannot say for sure the exact reasons, some potential causes included a substance use or mental health relapse, moving out of the area, or perhaps even incarceration.

Assessment of criminal justice outcomes focused primarily on self-reported nights in jail. Results of two-tailed paired sample $t$ tests indicated significant improvements 
Table 2 Preliminary outcomes

\begin{tabular}{|c|c|c|c|c|}
\hline & Baseline mean $(S D)$ & 6-Month mean $(S D)$ & $d f$ & $t$ \\
\hline \multirow[t]{2}{*}{ Nights in jail in last 6 months } & $61.18(52.83)$ & $33.94(54.72)$ & 66 & 0.001 \\
\hline & Baseline \% & 6-Month \% & $p$ & \\
\hline \multicolumn{5}{|l|}{ Service use } \\
\hline Inpatient physical & 3.0 & 3.0 & 1.000 & \\
\hline Inpatient mental/emotional & 0 & 0 & - & \\
\hline Inpatient substance & 20.9 & 1.5 & 0.001 & \\
\hline Outpatient physical & 14.9 & 32.8 & 0.008 & \\
\hline Outpatient mental/emotional & 13.4 & 20.9 & 0.227 & \\
\hline Outpatient substance & 6.0 & 6.0 & 1.000 & \\
\hline ER physical & 6.0 & 11.9 & 0.344 & \\
\hline ER mental/emotional & 0 & 0 & - & \\
\hline ER substance & 1.5 & 0 & - & \\
\hline Employed full or part time & 28.8 & 60.6 & 0.00002 & \\
\hline Employed full time & 16.7 & 48.5 & 0.00005 & \\
\hline Used alcohol in last 30 days & 4.5 & 3.0 & 1.000 & \\
\hline Used alcohol in last 6 months & 36.4 & 10.6 & 0.0005 & \\
\hline Used drugs in last 30 days & 7.5 & 4.5 & 0.687 & \\
\hline Used drugs in last 6 months & 51.5 & 19.7 & 0.0002 & \\
\hline
\end{tabular}

from baseline to 6-month follow-up, with an average reduction from $61.18(S D=52.83)$ nights spent in jail during the 6 months prior to baseline to $33.94(S D=54.72)$ nights during the first 6 months of treatment $[t(66)=3.567$, $p=0.001]$.

Employment was operationalized as the percentage of clients employed full time and percentage of clients with any kind of employment. Results of McNemar's tests on numbers of clients with full time employment and those with any employment indicated significant improvements from baseline to 6-month follow-up in both categories. Full time employment improved from 16.7 to $48.5 \%(p<0.001)$, and overall employment (part time or full time) improved from 28.8 to $60.6 \%$ during the first 6 months of the treatment $(p<0.001)$.

With regard to substance use, analyses revealed significant reductions in the percentages of clients who reported alcohol (36.4-10.6\%) and drug use (51.5-19.7\%) during the first 6 months of the treatment program compared to the 6 months prior to enrollment ( $p<0.001$ for alcohol; $p<0.001$ for drugs).

With regard to service utilization, clients experienced a slight (but not statistically significant) increase in the use of outpatient community mental health services beyond the MISSION-CJ services (13.4\% pre-intervention compared with $20.9 \%$ at 6 months). However, McNemar's tests showed a significant decrease in the percentage of patients reporting inpatient hospitalizations for substance use $(p=0.001)$, and a significant increase in clients reporting use of outpatient care for physical symptoms $(p=0.008)$.

\section{Discussion}

To our knowledge, this is the first effort to report on the systematic integration of a co-occurring disorder and criminal justice treatment in drug courts. This design is unique compared to typical drug court treatment that involves the court making a referral to a community provider to deliver cooccurring disorder treatment services as usual and parallel but not integrated with court case processing and probation. The MISSION-CJ intervention was able to be implemented and embedded within drug court and probation procedures. Preliminary program outcomes suggest that clients demonstrated significant reductions in the number of jail days, decreased substance use, and increased employment, which we at least in part attribute to the MISSION-CJ services. The clients also demonstrated reduced hospitalizations and increased linkages to medical providers. These improvements were observed despite a small sample being enrolled in the service across two courts, suggesting that individuals can achieve success in key social domains while undergoing treatment using the MISSION-CJ protocol. However, it is also possible that clients might continue to show even more improvement over time given this was only a 6-month follow-up period. 
Despite the limitations of a pre-test/post-test design, we believe these improvements could have been due at least in part to the multifactorial features of the MISSION-CJ protocol, including incorporation of the Critical Time Intervention approach that assists clients in actively engaging with community supports (Tomita and Herman 2015; Draine and Herman 2007). Additionally, the gains made by this group in employment have likely been associated with reduced jail days. A number of criminological theorists take the view that individuals' likelihood of offending and reoffending is significantly reduced by access to gainful employment, which is also supported by research findings (Laub and Sampson 2001; Ministry of Justice 2013). Moreover, employment improves individuals' economic situations, thereby reducing their need to engage in illicit behavior to acquire necessities of life. However, we believe that the success of the program goes beyond just increasing rates of employment. MISSIONCJ includes a complex array of evidence-based practices, which in this study, were integrated within, as opposed to alongside existing court procedures, in an attempt to reduce service fragmentation and increase communication between probation, the court and the client. In its overarching framework, MISSION-CJ is unique in that it takes a deliberate and systematized approach to addressing criminogenic risk and needs to reduce recidivism as a recovery goal for participants. In a previous study, we integrated MISSION-CJ alongside probation but separate from a specialized treatment court docket, and found it to be effective for increasing communication between the court, probation, and providers (Smelson et al. 2015).

In addition to the constraints associated with a pretest/post-test design, which include a lack of a comparison group and the fact that over time, clients might have improved irrespective of MISSION-CJ services, other limitations should be noted. This study only included a 6 month follow up period, and longer follow up data might have revealed a negative effect on outcomes. Although long-term outcomes are not fully known with this program evaluation study, other reports have suggested that the first few months are a critical period for engaging clients in treatment, lending further support for our findings (Binswanger et al. 2007). Other limitations included that our service providers did not consistently have available space within the court to deliver MISSION-CJ services nor did they consistently track the contacts delivered inside the court setting versus in the community. However, with regard to implementation, MISSION-CJ staff served as regular members of the pre-court meeting, offering ongoing collaboration to the court and probation services and had contacts with clients between sessions. A final limitation was with regard to self-reported data, such as jail days and re-arrest, which are best captured in rigorous methodically driven studies by official record data. For this study, that information was not available as criminal justice records were kept by several separate agencies distinct from the information available to us. Nonetheless, self-report data is routine in program evaluation contexts as a means of judging the effectiveness of a service delivery model (SAMHSA 2010). Given that this was intended to be a pilot study of our ability to integrate MISSION-CJ in drug courts, additional research is needed to confirm the extent to which the improvements could be attributed to the MISSION-CJ services and not just time in the drug court. That said, assuming that MISSION-CJ is an augmentation strategy to make drug courts even more effective, future evaluations need to (a) identify factors associated with dropout/loss to follow-up and determine what possible modifications could be made to reduce such attrition; and (b) assess the effects of MISSION-CJ at 12 months and, if possible, at various points thereafter. Finally, there is a critical need to conduct a randomized controlled trial of MISSION-CJ and drug courts in general to make the ultimate determination of its true efficacy and effectiveness. We believe, however, that the data reported here demonstrate the feasibility of implementing MISSION-CJ within a drug court protocol, and have observed, even with a small sample, effects sufficiently robust to justify further research.

Acknowledgements We thank the Gavin Foundation, the University of Massachusetts, the Massachusetts Department of Public Health, Massachusetts Department of Mental Health and the Executive Office of the Trial Court for supporting this work. Co-author Mary-Kate Duffy is no longer affiliated with the University of Massachusetts Medical School.

Funding This work was funded by a grant from the Substance Abuse and Mental Health Services Administration (1H79TI025074-03).

\section{Compliance with Ethical Standards}

Conflict of interest The authors report no known conflicts of interest and certify responsibility for the manuscript submitted.

Disclosure The views expressed in this article are those of the authors and do not necessarily reflect the position or policy of the University of Massachusetts, the Department of Public Health, the Department of Mental Health, or the Massachusetts Executive Office of the Trial Court or United States Governments.

Ethical Approval This open pilot was reviewed by the University of Massachusetts Medical School's Institutional Review Board and was determined to be program evaluation rather than human subjects research.

Research Involving Human Participants This article does not contain any studies with human participants performed by any of the authors. 


\section{References}

Andrews, D. A., \& Bonta, J. (2006). The psychology of criminal conduct (4th ed.). Newark, NJ: LexisNexis.

Andrews, D. A., Bonta, J., \& Hoge, R. D. (1990). Classification for effective rehabilitation: Rediscovering psychology. Criminal Justice and Behavior, 17(1), 19-52. https://doi. org/10.1177/0093854890017001004.

Belenko, S. (2001). Research on drug courts: A critical review, 2001 update. New York, NY: National Center on Addiction and Substance Abuse, Columbia University. Retrieved October 5, 2016, from https://pdfs.semanticscholar.org/1450/f4776d89877366b d93b1a696c1040c30adae.pdf.

Binswanger, I., Stern, M. F., Deyo, R. A., Heagerty, P. J., Cheadle, A., Elmore, J. G., \& Koepsell, T. D. (2007). Release from prison-A high risk of death for former inmates. The New England Journal of Medicine, 356, 157-165. https://doi. org/10.1056/NEJMsa064115.

Bonta, J., \& Andrews, D. A. (2007). Risk-need-responsivity model for offender assessment and rehabilitation (Corrections Research User Report No. 2007-06). Ottawa, Ontario: Public Safety Canada. Retrieved January 23, 2017 from https://cpoc. memberclicks.net/assets/Realignment/risk_need_2007-06_e. pdf.

Brown, R. T. (2010). Systematic review of the impact of adult drugtreatment courts. Translational Research, 155(6), 263-274. https://doi.org/10.1016/j.trsl.2010.03.001.

Case, B., Steadman, H. J., Dupuis, S. A., \& Morris, L. S. (2009). Who succeeds in jail diversion programs for persons with mental illness? A multi-site study. Behavioral Sciences \& the Law, 27(5), 661-674.

Chinman, M., George, P., Doughtery, R. H., Daniels, A. S., Ghose, S. S., Swift, A., \& Delphin-Rittmon, M. E. (2014). Peer support services for individuals with serious mental illnesses: Assessing the evidence. Psychiatric Services, 65(4), 429-441. https://doi. org/10.1176/appi.ps.201300244.

Chinman, M., Shoai, R., \& Cohen, A. (2010). Using organizational change strategies to guide peer support technician implementation in the Veterans Administration. Psychiatric Rehabilitation Journal, 33(4), 269-277.

Draine, J., \& Herman, D. B. (2007). Critical time intervention for re-entry from prison for persons with mental illness. Psychiatric Services, 58(12), 1577-1581. https://doi.org/10.1176/ ps.2007.58.12.1577.

Epperson, M. W., Wolff, N., Morgan, R. D., Fisher, W. H., Frueh, B. C., \& Huening, J. (2014). Envisioning the Next Generation of Behavioral Health and Criminal Justice Interventions. International Journal of Law and Psychiatry, 37(5), 427-438.

Fox, A. D., Maradiaga, J., Weiss, L., Sanchez, J., Starrels, J. L., \& Cunningham, C. O. (2015). Release from incarceration, relapse to opioid use and the potential for buprenorphine maintenance treatment: A qualitative study of the perceptions of former inmates with opioid use disorder. Addiction Science and Clinical Practice, 10, 2.

Knudsen, K. J., \& Wingenfeld, S. (2016). A specialized treatment court for veterans with trauma exposure: Implications for the field. Community Mental Health Journal, 52(2), 127-135.

Laub, J. H., \& Sampson, R. J. (2001). Understanding Desistance from Crime. Crime and Justice, 28(1), 1-69.

Maintaining Independence and Sobriety through Systems Integration, Outreach, and Networking (MISSION). Intervention summary retrieved on November 18, 2016 from the Substance Abuse and Mental Health Services Administration's National Registry of Evidence-based Programs and Practices. http:// nrepp. samhsa.gov/ProgramProfile. $a s p x ? i d=38$.
McLellan, A. T., Kushner, H., Metzger, D., Peters, R., Smith, I., Grissom, G., Pettinati, H., \& Argeriou, M. (1992). The fifth edition of the addiction severity index. Journal of Substance Abuse Treatment, 9(3), 199-213.

Ministry of Justice. (2013). Analysis of the impact of employment on reoffending following release from custody, using propensity score matching. Retrieved December 3, 2016, from https://www.gov.uk/ government/uploads/system/uploads/attachment_data/file/21741 2/impact-employment-reoffending.pdf.

O’Connor, K., Kline, A., Sawh, L., Rodrigues, S., Fisher, W., Kane, W., Kuhn, J., Ellison, M., \& Smelson, D. (2012). Unemployment and co-occurring disorders among homeless veterans. Journal of Dual Diagnosis, 9(2), 134-138. https://doi.org/10.1080/15504 263.2013.778804.

Peters, R. H., Kremling, J., Bekman, N. M., \& Caudy, M. S. (2012). Co-occurring disorders in treatment-based courts: Results of a national survey. Behavioral Sciences \& the Law, 30(6), 800-820. https://doi.org/10.1002/bsl.2024.

Pinals, D. A., Smelson, D., Sawh, L., Harter, J., Kline, A., \& Ziedonis, D. (2014). The MISSION-CJ treatment manual. Worcester, MA: UMass Medical School.

Piquero, A. (2010). Cost-benefit analysis for jail alternatives and jail. Report to Broward Sheriff's Office Department of Community Control. Retrieved August 3, 2016, from http://criminology.fsu. edu/wp-content/uploads/Cost-Benefit-Analysis-for-Jail-Alternativ es-and-Jail.pdf.

Smelson, D., Kalman, D., Losonczy, M. F., Kline, A., Sambamoorthi, U., St. Hill, L., Castles-Fonseca, K., \& Ziedonis, D. (2012). A brief treatment engagement intervention for individuals with cooccurring mental illness and substance use disorders: Results of a randomized clinical trial. Community Mental Health Journal, 48(2), 127-132.

Smelson, D., Kline, A., Kuhn, J., Rodrigues, S., O'Connor, K., Fisher, W., Sawh, L., \& Kane, V. (2013). A wraparound treatment engagement intervention for homeless veterans with co-occurring disorders. Psychological Services, 10(2), 161-167.

Smelson, D., Losonczy, M., Ziedonis, D., Sussner, B., Castles-Fonseca, K., Rodrigues, S., \& Kline, A. (2007). A brief community linkage intervention for veterans with a persistent mental illness and a co-occurring substance abuse disorder. European Journal of Psychiatry, 21(2), 143-152.

Smelson, D., Pinals, D. A., Harter, J., Sawh, L., Kline, A., \& Ziedonis, D. (2014). The MISSION-CJ participant workbook. Worcester, MA: UMass Medical School.

Smelson, D., Pinals, D. A., Sawh, L., Fulwiler, C., Singer, S., Guevremont, N., Fisher, W., Steadman, H. J., \& Hartwell, S. (2015). An alternative to incarceration: Co-occurring disorders treatment intervention for justice-involved veterans. World Medical \& Health Policy, 7(4), 329-348. https://doi.org/10.1002/wmh3.168/ abstract.

Steadman, H. J., Davidson, S., \& Brown, C. (2001). Law and psychiatry: Mental health courts: Their promise and unanswered questions. Psychiatric Services, 52(4), 457-458. https://doi. org/10.1176/appi.ps.52.4.457.

Steadman, H. J., Peters, R. H., Carpenter, C., Mueser, K. T., Jaeger, N. D., Gordon, R. B., Fisler, C., Goss, S., Olson, E., Osher, F. C., Noether, C. D., \& Hardin, C. (2013). Six Steps to Improve Your Drug Court Outcomes for Adults with Co-Occurring Disorders. SAMHSA's GAINS Center for Behavioral Health and Justice Transformation's \& National Drug Court Institute's Drug Court Practitioner Fact Sheet, Vol. 8, No. 1. Retrieved September 27. 2016, from https://csgjusticecenter.org/mental-health/publicatio ns/six-steps-to-improve-your-drug-court-outcomes-for-adult s-with-co-occurring-disorders.

Substance Abuse \& Mental Health Services Administration. (2006). "National Outcome Measures (NOMs) for Co-Occurring 
Disorders." Substance Abuse \& Mental Health Services Administration, U.S. Department of Health and Human Services. Retrieved December 14, 2016, from https://ntrl.ntis.gov/NTRL/ dashboard/searchResults/titleDetail/PB2012107168.xhtml.

Substance Abuse and Mental Health Services Administration. (2010). GPRA Modernization Act of 2010. Substance Abuse and Mental Health Services Administration, U.S. Department of Health and Human Services. Retrieved from http://www.samhsa.gov/grants/ gpra-measurement-tools/csap-gpra.

Susser, E., Betne, P., Valencia, E., Goldfinger, S. M., \& Lehman, A. (1997). Injection drug use among homeless adults with severe mental illness. American Journal of Public Health, 87(5), 854-856.

Taxman, F. S., \& Thanner, M. (2006). Risk, need, and responsivity (RNR): It all depends. Crime and Delinquency, 52(1), 28-51.

Tomita, A., \& Herman, D. (2015). The role of a critical time intervention on the experience of continuity of care among persons with severe mental illness following hospital discharge. Journal of Nervous and Mental Disease, 203(1), 65-70.

Trojano, M. L., Christopher, P. P., Pinals, D. A., Harnish, A., \& Smelson, D. (2017). Perceptions of voluntary consent among jail diverted veterans with co-occurring disorders. Behavioral Sciences \& the Law. https://doi.org/10.1002/bsl.299.

Wolff, N. B., Frueh, C., Huening, J., Shi, J., Epperson, M. W., Morgan, R., \& Fisher, W. (2013). Practice informs the next generation of behavioral health and criminal justice interventions. International Journal of Law and Psychiatry, 36, 1-10.

Zarkin, G. A., Cowell, A. J., Hicks, K. A., Mills, M. J., Belenko, S., Dunlap, L. J., \& Keyes, V. (2015). Lifetime benefits and costs of diverting substance-abusing offenders from state prison. Crime and Delinquency, 61(6), 829-850.

Ziedonis, D., \& Stern, R. (2001). Dual recovery therapy for schizophrenia and substance abuse. Psychiatric Annals, 31(4), 226-232. 